\title{
The correlation between family food handling behaviors and foodborne acute gastroenteritis: a community-oriented, population-based survey in Anhui, China
}

\author{
Yujuan Chen * (D), Yufeng Wen, Jiangen Song, Baifeng Chen, Shushu Ding, Lei Ding and Jiajia Dai
}

\begin{abstract}
Background: Foodborne acute gastroenteritis is a significant public health concern. Food handling plays a key role in the risk of foodborne acute gastroenteritis. However, research focused on the correlation between foodborne acute gastroenteritis and food handling in the family environment is limited. The purpose of the current study was to determinate the association between food handling behaviors in the family environment and foodborne acute gastroenteritis.

Methods: A cross-sectional investigation was conducted from September 1, 2015 to August 30, 2016 in Anhui Province, China. A multistage stratified cluster sampling method was designed to select subjects. Data on foodborne acute gastroenteritis and food handling were collected via questionnaire survey.

Results: Of the 1516 subjects included in the study, 165 (10.9\%) reported having experienced symptoms of foodborne acute gastroenteritis in the past 4 weeks. The following behaviors were more prevalent in those that experienced acute gastroenteritis: (1) infrequently thoroughly heating milk (75.6\%); (2) infrequently thoroughly heating cooked food purchased from outside (71.3\%); (3) infrequently thoroughly heating leftovers stored in the refrigerator (32.5\%), and (4) infrequently storing leftovers in the refrigerator (41.6\%). A multivariate logistic regression analysis found that foodborne acute gastroenteritis was associated with the following behaviors: (1) often eating raw seafood $(P<0.001, \mathrm{OR}=3.250,95 \% \mathrm{Cl}=2.136-4.946)$; (2) often storing raw meat and cooked meat in the same container $(P<0.001, \mathrm{OR}=4.291,95 \% \mathrm{Cl}=2.722-6.765)$; (3) infrequently thoroughly heating milk $(P<0.001$, $\mathrm{OR}=4.665,95 \% \mathrm{Cl}=2.526-8.617)$; (4) infrequently thoroughly heating leftovers stored in the refrigerator $(P<0.001$, $\mathrm{OR}=3.416,95 \% \mathrm{Cl}=2.139-5.454)$; $(5)$ infrequently storing leftovers in the refrigerator $(P<0.05, \mathrm{OR}=1.775,95 \%$ $\mathrm{Cl}=1.169-2.696)$; and (6) infrequently thoroughly cooking green beans $(P<0.001, \mathrm{OR}=2.859,95 \% \mathrm{Cl}=1.798-4.545)$.
\end{abstract}

Conclusions: Poor food handling behaviors in the family environment are associated with foodborne acute gastroenteritis. Infrequent thorough heating and improper food storage are the most critical risk factors in foodborne acute gastroenteritis.

Keywords: Foodborne acute gastroenteritis, Incidence, Correlation, Food handling, Family environment

\footnotetext{
* Correspondence: 57903241@qq.com

School of public health, Wannan Medical College, 22 West Wenchang Road,

Wuhu 241002, Anhui Province, China
}

(c) The Author(s). 2018 Open Access This article is distributed under the terms of the Creative Commons Attribution 4.0 International License (http://creativecommons.org/licenses/by/4.0/), which permits unrestricted use, distribution, and reproduction in any medium, provided you give appropriate credit to the original author(s) and the source, provide a link to the Creative Commons license, and indicate if changes were made. The Creative Commons Public Domain Dedication waiver (http://creativecommons.org/publicdomain/zero/1.0/) applies to the data made available in this article, unless otherwise stated. 


\section{Background}

Foodborne acute gastroenteritis is an important cause of morbidity and mortality, especially in developing countries [1]. Over the past 20 years, the burden of foodborne acute gastroenteritis caused by specific pathogens has been estimated using the combined data obtained from the Foodborne Diseases Active Surveillance Network, community population surveys, or hospital records. However, the global burden of foodborne acute gastroenteritis remains unknown. The World Health Organization reported that there were approximately 600 million foodborne cases with 420,000 associated deaths in 2010 [2]. In the United States, the Center for Disease Control received reports of 13,405 foodborne disease outbreaks between 1998 and 2008, including 273,120 reported cases of foodborne disease, 9109 hospitalizations, and 200 deaths [3]. In Australia, 444 outbreaks of gastroenteritis and foodborne disease were reported in 2003, 99 of these outbreaks were caused by food, resulting in 1686 individual cases, 105 hospitalizations, and nine deaths [4]. In Iran, a total of 2250 gastroenteritis outbreaks were reported from 2006 to 2011 [5]. Several population-based investigations from France, Poland, Italy and Barbados have reported that 2.5, 6.7, 7.9 , and $4.9 \%$, of respondents, respectively, experienced acute gastroenteritis [6-9]. In China [10], the proportion of acute gastroenteritis cases reported by respondents was $3.2 \%$ from 2010 to 2011 .

Microorganisms, chemicals, and parasites are the leading contaminants associated with foodborne acute gastroenteritis, with microorganisms as the most common causative factor [11]. Food contamination can occur at any point along the food production chain including the food preparation process in the family environment. To reduce the risk of foodborne acute gastroenteritis, the entire food production chain must be monitored. Many countries have already adopted government oversite devoted to the reduction of foodborne risk and have decreased the incidence of foodborne acute gastroenteritis. Nevertheless, foodborne disease remains a major public health issue worldwide.

The family environment is the last step in the food handling chain from farms and food processing plants to the table. Research from Australia and New Zealand have reported that approximately $20-50 \%$ of foodborne diseases were attributed to the home environment [12]. Approximately $36.4 \%$ of foodborne outbreaks reported by the European Union were caused by inappropriate food handling practices in the home [13]. In 2015, the Foodborne Diseases Active Surveillance Network in China received reports of 79 food poisoning incidents in the family, resulting in 1510 individual cases of food poisoning, and four deaths [14]. Understanding food poisoning arising from the home environment, is therefore critical.
In China, microorganisms, chemicals, and poisonous animals and plants are the most commonly reported pathogenic factors leading to foodborne disease $[15,16]$. Fruits and vegetables, beans and dairy products, flour and rice foods, meat and meat products, milk products and seafood are the foods most commonly associated with foodborne diseases in China [17]. Residual pesticides and nitrites are the main pathogenic factors found in fruits and vegetables [18]. Food poisoning is also caused by eating undercooked or raw poisonous animals and plants. For example, food poisoning incidents caused by undercooked green beans, and undercooked and raw seafood are frequent in China [19-21]. In addition, leftover foods that have not been properly refrigerated are high risk foods for foodborne diseases [22-24]. The majority of Chinese people drink milk daily due to the high nutritional value. However, outbreaks of food poisoning caused by milk without heating are frequently reported [25-27].

The National Health and Family Planning Commission of the People's Republic of China reported that inappropriate food handling and storage, cross contamination, and misuse of poisonous foods are the main causes of food poisoning in student cafeterias $[28,29]$. The results of a survey on knowledge about, attitudes toward, and the practice of food safety showed that inappropriate food handling, such as cross-contamination, improper defrosting of frozen foods, improper storage time and temperature, and inadequate cooking, are potential risk factors for foodborne diseases [30-32]. However, to date, data on the correlation between foodborne acute gastroenteritis and food handling in the family environment in China are limited. We hypothesized that poor food handling behaviors, including inappropriate heating of foods, such as milk, leftovers, and green beans, inappropriate storage of leftovers, cross contamination of food, eating raw or undercooked food, purchasing stale food, and incomplete disinfection of kitchen utensils are associated with foodborne acute gastroenteritis. The current research aimed to examine correlations between food handling behaviors in the family environment and foodborne acute gastroenteritis.

\section{Methods}

A cross-sectional survey was conducted in Anhui Province, China on the correlation between food handling in the family environment and foodborne acute gastroenteritis among individuals aged 18 and over. The survey was conducted from September 1, 2015 to August 30, 2016. The medical ethics committee of Wannan Medical College, Anhui Province, China approved study procedures. Signed informed consent was obtained from all participants or a legal representative. 


\section{Study populations and sampling design}

A multistage stratified cluster sampling method was applied to select subjects in Anhui Province in 2015. Survey areas were selected based on environmental conditions, population size, economic level, culture, and lifestyle. In the first stage, 6 cities (Hefei, Fuyang, Wuhu, Suzhou, Xuancheng, and Chizhou) were selected randomly from a total of 17 cities (Hefei, Wuhu, Ma-anshan, An-qing, Chaohu, Bengbu, Huaibei, Liu-an, Tongling, Huainan, Xuancheng, Chuzhou, Huangshan, Fuyang, Haozhou, Suzhou, and Chizhou) in Anhui Province. One district and one county from each of the six cities was then randomly selected. In the second stage, two streets and two towns were selected randomly from each district and each county, respectively. In the third stage, one community and one administrative village was selected from each street and town, respectively, resulting in a total of 24 sites (12 communities and 12 administrative villages). In the fourth stage, 1600 households were randomly sampled from the 24 sites. Of the 1600 households selected, 84 declined participation, resulting in 1516 (94.8\%) households that completed interviews.

\section{Data collection}

Approximately 100 to 150 different households were interviewed each month. Over a 12-month period, 1516 households were surveyed. In each household, the individual celebrating his/her birthday next was selected to participate in the survey. For those younger than 12 years old, the questions were answered by parents or guardians. Interviews were conducted by trained investigators using a questionnaire designed specifically for this study. Data gathered from the questionnaire included: (1)general demographic characteristics; (2) occurrence of acute gastroenteritis over the past 4 weeks; (3) behavior of food purchasing, handling, storage, and consumption. All subjects were asked whether they had experienced diarrhea or vomiting in the four weeks prior to the survey. In cases where diarrhea or vomiting were reported, details with respect to possible causes, the suspected food(s), and the origin of suspected foods were recorded. Information related to the behavior of food purchasing, handling, storage, and consumption were obtained from subjects $\geq 18$ years old, who were the primary food handlers in the family.

\section{Case definition}

Acute gastroenteritis was defined as diarrhea and/or vomiting for a period of at least $24 \mathrm{~h}$ within the 4 weeks preceding the interview. Diarrhea was defined as at least three loose-stool bowel movements within a 24-h period. Vomiting was recorded only if it was coupled with at least one other symptom (abdominal pain, nausea, or fever). Cases of diarrhea or vomiting caused by irritable bowel syndrome, colitis, colon diverticulitis, pregnancy, chemotherapy/radiotherapy, medication, food allergy, Crohn's disease, and excess alcohol were excluded from the data set. Respondents who experienced symptoms of foodborne acute gastroenteritis were referred to as the "case group". Respondents who did not experience symptoms of foodborne acute gastroenteritis were referred to as the "control group".

\section{Statistical analysis}

The database was constructed using EpiData 3.1 software (EpiData, Odense, Denmark), and statistical analyses were performed using SPSS Software V.18.0 (SPSS Inc., Chicago, IL, USA). All qualitative data were expressed as frequency (percentage). The incidence of foodborne acute gastroenteritis was calculated by dividing the number of subjects reporting foodborne acute gastroenteritis in the four weeks prior to the survey by the total number of subjects. The proportion of those exposed to inappropriate food handling behavior was calculated as the number of subjects who engage regularly in inappropriate food handling behavior relative to the total number of subjects. A chi-square test was used to compare the following: (1) the incidence of foodborne acute gastroenteritis associated with different socio-demographic characteristics; (2) the proportion of those exposed to inappropriate food handling separated by gender; and (3) the proportion of those exposed to inappropriate food handling among cases of foodborne acute gastroenteritis and among those who did not report illness. Unconditional logistic regression was used to explore the association between food handling and foodborne acute gastroenteritis and to compute odds ratios and $95 \%$ confidence intervals $(95 \% \mathrm{CI})$. Linear regression was used to diagnose the collinearity of independent variables through tolerance value and the variance inflation factor (VIF). A Tolerance value $<0.1$ or a VIF- value $>10$ was considered indicative of collinearity. A $P$-value $<0.05$ was considered significant. Two-tailed tests were conducted.

\section{Results \\ Demographic characteristics of respondents}

Males comprised $56.5 \%$ of the subjects. Over $60 \%$ of subjects were between 18 years and 50 years old. The proportions of subjects aged $\leq 17$ years and $\geq 50$ years were 5.5 and $10.1 \%$, respectively. Most of the subjects (79.0\%) had a secondary or tertiary education. Almost $57.7 \%$ of respondents lived in rural areas and $42.3 \%$ in urban areas. Approximately $49.5 \%$ of the respondents reported that their annual household income was within the range of $30,000-89,999$ CNY (4387-13,161 USD), while $33.7 \%$ reported an annual household income greater than 90,000 CNY (13,161 USD). The remaining $17.0 \%$ of the subjects reported an annual household 
income of less than 30,000 CNY (4387 USD). Approximately $19 \%$ of the respondents were peasant migrant workers who commuted to the city from the countryside to work in the construction industry for six months or more, while approximately $13.7 \%$ of the respondents were peasant farm workers in rural areas. The percentage of respondents working as service staff, medical staff, and laborers (e.g. factory workers) were $10.1,15.4$, and $11.3 \%$, respectively. Finally, teachers accounted for $8.9 \%$ of the subjects, while students and children accounted for $4.7 \%$ of the subjects.
Incidence and distribution of foodborne acute gastroenteritis A total of 281 (18.5\%) respondents reported that they had experienced symptoms of acute gastroenteritis in the past 4 weeks. Of these respondents, $165(10.9 \%)$ cases were identified as foodborne acute gastroenteritis. As shown in Table 1. The monthly incidence of foodborne acute gastroenteritis was significantly higher in females $(15.3 \%)$ than in males $(7.5 \%, P<0.001)$. The incidence rate of gastroenteritis was significantly different among age groups $\left(\mathrm{X}^{2}=49.264, P<0.001\right)$, education level $\left(\mathrm{X}^{2}=11.116, P<0.05\right)$, and total family income $\left(\mathrm{X}^{2}=\right.$ 12.033, $P<0.01)$. There was a significant difference in

Table 1 The incidence and 95\% Cl of foodborne acute gastroenteritis among participants

\begin{tabular}{|c|c|c|c|c|c|c|}
\hline & \multirow{2}{*}{$\begin{array}{l}\text { Foodborne } \\
\text { gastro-enteritis (n) }\end{array}$} & \multirow{2}{*}{$\begin{array}{l}\text { Total } \\
\text { Participants } \\
\text { (n) }\end{array}$} & \multicolumn{2}{|c|}{ Monthly incidence } & \multirow[t]{2}{*}{$x^{2}$} & \multirow[t]{2}{*}{$P$} \\
\hline & & & $\%$ & $(95 \% \mathrm{Cl})$ & & \\
\hline Total & 165 & 1516 & 10.9 & $(9.4-12.6)$ & & \\
\hline \multicolumn{7}{|l|}{ Gender } \\
\hline male & 64 & 856 & 7.5 & $(5.5-9.2)$ & \multirow[t]{2}{*}{23.534} & \multirow[t]{2}{*}{$<0.001$} \\
\hline female & 101 & 660 & 15.3 & $(12.6-18.0)$ & & \\
\hline \multicolumn{7}{|l|}{ Age (years) } \\
\hline$\leq 17$ & 12 & 76 & 15.8 & $(7.9-23.7)$ & \multirow[t]{5}{*}{49.264} & \multirow[t]{5}{*}{$<0.001$} \\
\hline $18 \sim$ & 54 & 567 & 9.5 & $(7.1-12.0)$ & & \\
\hline $30 \sim$ & 45 & 315 & 14.3 & $(10.5-18.1)$ & & \\
\hline $40 \sim$ & 18 & 405 & 4.4 & $(2.5-6.4)$ & & \\
\hline$\geq 50$ & 36 & 153 & 23.5 & $(17.0-30.7)$ & & \\
\hline \multicolumn{7}{|l|}{ Education } \\
\hline primary school and below & 36 & 381 & 11.3 & $(7.9-14.8)$ & \multirow[t]{4}{*}{11.116} & \multirow[t]{4}{*}{0.011} \\
\hline junior high school & 49 & 387 & 12.7 & $(9.6-16.0)$ & & \\
\hline high school & 60 & 476 & 12.6 & $(9.5-15.5)$ & & \\
\hline bachelor and above & 20 & 335 & 6.0 & $(3.6-8.7)$ & & \\
\hline \multicolumn{7}{|l|}{ Total annual income (CNY) } \\
\hline$<30,000$ & 31 & 259 & 12.0 & $(8.1-15.8)$ & \multirow[t]{4}{*}{12.033} & \multirow[t]{4}{*}{0.007} \\
\hline $30,000-49,999$ & 31 & 299 & 10.4 & $(7.0-14.0)$ & & \\
\hline $50,000-89,999$ & 65 & 452 & 14.4 & $(11.3-17.7)$ & & \\
\hline$\geq 90,000$ & 38 & 506 & 7.5 & $(5.3-9.2)$ & & \\
\hline \multicolumn{7}{|l|}{ Residence } \\
\hline urban & 49 & 641 & 7.6 & $(5.9-9.8)$ & \multirow[t]{2}{*}{12.017} & \multirow[t]{2}{*}{0.001} \\
\hline rural & 116 & 875 & 13.3 & $(11.0-15.7)$ & & \\
\hline \multicolumn{7}{|l|}{ Occupation } \\
\hline students and children & 10 & 72 & 13.9 & $(6.9-22.2)$ & \multirow[t]{8}{*}{8.233} & \multirow[t]{8}{*}{0.312} \\
\hline service personal & 18 & 153 & 11.8 & $(7.2-17.6)$ & & \\
\hline teacher & 9 & 135 & 6.7 & $(3.0-11.1)$ & & \\
\hline medical staff & 18 & 234 & 7.7 & $(4.3-11.5)$ & & \\
\hline peasant worker & 38 & 290 & 13.1 & $(9.3-16.6)$ & & \\
\hline peasant & 27 & 207 & 13.0 & $(8.7-17.4)$ & & \\
\hline worker & 18 & 171 & 10.5 & $(5.8-15.2)$ & & \\
\hline other or unknown & 27 & 254 & 10.6 & $(7.5-14.6)$ & & \\
\hline
\end{tabular}


incidence of foodborne acute gastroenteritis between urban $(7.6 \%)$ and rural $(13.3 \%)$ residents $\left(\mathrm{X}^{2}=12.017, P<\right.$ $0.01)$. In addition, students and children had the highest incidence (13.9\%) of foodborne acute gastroenteritis, followed by peasant workers (13.1\%) and peasants $(13.0 \%)$, however, this difference did not reach significance $\left(\mathrm{X}^{2}=\right.$ $8.233, P>0.05)$.

\section{Suspected food and food origin}

In the current study, foods suspected of causing illness were divided into eight categories, including: (1) meat and meat product; (2) milk and dairy products; (3) egg and egg products; (4) aquatic products; (5) cereals and cereal products (including rice, wheat flour, maize, mille, buckwheat and other starchy foods such as potato, sweet potato, and taro); (6) beans and bean products; (7) vegetable oil; and (8) fruits and vegetables. As shown in Table 2 , the most frequently suspected food was meat and meat products $(58.2 \%)$, followed by milk and dairy products (17.6\%) and aquatic products (10.9\%). The most common location of suspected food origin was home (40.6\%), followed by street food stalls $(24.8 \%)$, and fast food restaurants (15.2\%).

The status of food handling in the family environment As can be seen in Table 3, from a total of 1440, the proportion of respondents who answered "no" to the items: "often thoroughly heat milk", "often thoroughly heat leftovers stored in the refrigerator", "often thoroughly heat cooked food purchased from outside", "often thoroughly heat green beans", and who answered "yes" to

Table 2 Constituent ratio of suspected food and food origin

\begin{tabular}{lll}
\hline Suspected food and food origin & Cases (n) & Constituent ratio (\%) \\
\hline Suspected food & 96 & 58.2 \\
meat and meat products & 29 & 17.6 \\
milk and dairy products & 9 & 5.5 \\
egg and egg products & 14 & 10.9 \\
aquatic products & 0 & 0.0 \\
cereals and cereal products & 9 & 5.5 \\
beans and bean products & 0 & 0.0 \\
vegetable oil & 6 & 3.6 \\
fruits and vegetables & 2 & 1.2 \\
other and unknown & & \\
Origin & 67 & 40.6 \\
home & 5 & 3.0 \\
hotels & 25 & 15.2 \\
fast food restaurants & 18 & 10.9 \\
food supermarket & 41 & 24.8 \\
street food stalls & 9 & 5.5 \\
other and unknown & &
\end{tabular}

Table 3 Comparison of food handling behaviors between male and female respondents

\begin{tabular}{llllll}
\hline Behavior Total $\mathrm{n}(\%)$ & Male $\mathrm{n}(\%)$ & Female $\mathrm{n}(\%)$ & $\mathrm{X}^{2}$ & $\mathrm{P}$ \\
\hline Often thoroughly heat cooked food purchased from outside before eating
\end{tabular}

$\begin{array}{llllll}\text { no } & 1026(71.3) & 621(76.7) & 405(64.3) & 26.518 & <0.001 \\ \text { yes } & 414(28.7) & 189(23.3) & 225(35.7) & & \end{array}$

Often thoroughly heat milk before drinking

$\begin{array}{llllll}\text { no } & 1089(75.6) & 621(76.7) & 468(74.3) & 1.090 & 0.297 \\ \text { yes } & 351(24.4) & 189(23.3) & 162(25.7) & & \end{array}$

Often store leftovers in the refrigerator

$\begin{array}{llllll}\text { no } & 468(32.5) & 225(27.8) & 243(38.6) & 18.820 & <0.001 \\ \text { yes } & 972(67.5) & 585(72.2) & 387(61.4) & & \end{array}$

Often thoroughly heat leftovers stored in the refrigerator before eating

$\begin{array}{llllll}\text { no } & 599(41.6) & 459(56.7) & 140(22.2) & 173.063<0.001 \\ \text { yes } & 841(58.4) & 351(43.3) & 490(77.8) & & \end{array}$

Often thoroughly clean raw vegetables or meat purchased from outside

$\begin{array}{llllll}\text { no } & 285(19.8) & 177(21.9) & 108(17.1) & 4.950 & 0.026\end{array}$

yes $\quad 1155(80.2) \quad 633(78.1) \quad 522(82.9)$

Often eat raw seafood

$\begin{array}{llllll}\text { no } & 1224(85.0) & 684(84.4) & 540(85.7) & 0.448 & 0.507 \\ \text { yes } & 216(15.0) & 126(15.6) & 90(14.3) & & \end{array}$

Often store raw meat and cooked meat in the same container

$\begin{array}{llllll}\text { no } & 1171(76.4) & 630(77.8) & 541(85.9) & 15.288 & <0.001 \\ \text { yes } & 269(23.6) & 180(22.2) & 89(14.1) & & \end{array}$

Often thoroughly heat green beans prior to eating

$\begin{array}{llllll}\text { no } & 249(17.3) & 184(22.7) & 65(10.3) & 38.091 & <0.001 \\ \text { yes } & 1191(82.7) & 626(77.3) & 565(89.7) & & \end{array}$

Often thoroughly boil kitchen utensils to disinfect

$\begin{array}{llllll}\text { no } & 1039(72.2) & 594(73.3) & 445(70.6) & 1.284 & 0.257 \\ \text { yes } & 401(27.8) & 216(26.7) & 185(29.4) & & \end{array}$

Often buy expired packaged food in supermarkets or shops

$\begin{array}{llllll}\text { no } & 1053(73.1) & 585(72.2) & 468(74.3) & 0.768 & 0.381\end{array}$

yes $\quad 387(26.9) \quad 225(27.8) \quad 162(25.7)$

Often Purchase stale raw vegetables, meat and other ingredients

$\begin{array}{llllll}\text { no } & 1023(71.0) & 540(66.7) & 483(76.7) & 17.222 & <0.001 \\ \text { yes } & 417(29.0) & 270(33.3) & 147(23.3) & & \end{array}$

Often eat outside the home

\begin{tabular}{llllll} 
no & $1238(86.0)$ & $698(86.2)$ & $540(85.7)$ & 0.062 & 0.804 \\
yes & $202(14.0)$ & $112(13.8)$ & $90(14.3)$ & & \\
\hline
\end{tabular}

the item "often eat raw seafood" were 75.6, 41.6, 71.3, 17.3 , and $15.0 \%$, respectively. The proportion of respondents who answered "no" to "often thoroughly boil disinfection kitchen utensils" and "often store leftovers in the refrigerator" were 72.2 and $32.5 \%$, respectively. In addition, approximately $29.0 \%$ of respondents often purchase stale raw vegetables, meat, and other ingredients. Stale, raw vegetables were defined as those that had been 
maintained in the market for a prolonged period of time before being purchased, and the edges of the leaves had begun to turn yellow and rot. Approximately $26.9 \%$ of respondents reported that they often buy expired packaged food. Almost 23.6\% of respondents often store raw meat and cooked meat in the same container, while $19.8 \%$ of respondents answered "no" to "often thoroughly clean raw vegetables or meat purchased from the market before cooking".

Male and female respondents differed significantly in their answers to the following food handling behaviors: "often thoroughly heat cooked food purchased from outside" $\left(X^{2}=26.518, P<0.001\right)$, "often thoroughly heat leftovers stored in the refrigerator" $\left(X^{2}=173.063, P<0.001\right)$, "often thoroughly cook green beans" $\left(\mathrm{X}^{2}=38.091\right.$, $P<0.001)$, "often store leftovers in the refrigerator" $\left(\mathrm{X}^{2}=18.820, P<0.001\right)$, "often thoroughly clean raw vegetables or meat purchased from outside" $\left(\mathrm{X}^{2}=4.950\right.$, $P<0.05)$, "often store raw meat and cooked meat in the same container" $\left(\mathrm{X}^{2}=15.288, P<0.001\right)$, and "often purchase stale raw vegetables, meat and other ingredients" $\left(X^{2}=17.222, P<0.001\right)$.

\section{Comparison of food handling behaviors between the case group and the control group}

Of the 1440 respondents, 153 reported experiencing foodborne acute gastroenteritis in the previous four weeks and are referred to as the "case group". The remaining 1287 respondents are referred to as the "control group". As seen in Table 4, the proportions of those that answered no to "often thoroughly heat milk" $\left(X^{2}=14.768, P<0.001\right)$, "often store leftovers in the refrigerator" $\left(X^{2}=5.875, P<0.05\right)$, "often thoroughly heat leftovers stored in the refrigerator" $\left(\mathrm{X}^{2}=\right.$ $29.597, P<0.001)$, and "often thoroughly cook green beans" $\left(\mathrm{X}^{2}=21.581, \mathrm{P}<0.001\right)$ and yes to "often eat raw seafood" $\left(X^{2}=55.298, P<0.001\right)$ and "often store raw meat and cooked meat in the same container" $\left(X^{2}=53.764, P<\right.$ 0.001 ), were significantly higher in the case group compared to the control group.

\section{Multivariable logistic regression analysis}

A multivariable logistic regression was conducted to analyze the association between food handling behaviors and foodborne acute gastroenteritis. Gender, age, occupation, residence, education, economic status, eating out, and food handling behaviors were independent variables, while foodborne acute gastroenteritis was the dependent variable. As shown in Table 5, after eliminating the effects of demographic characteristics on foodborne acute gastroenteritis, the behaviors entered into the regression were: "often thoroughly heat milk before eating" $(P<0.001$, OR $=4.665,95 \% \mathrm{CI}=2.526-8.617$ ), "often thoroughly heat leftovers stored in the refrigerator before eating" $(P<0.001$, $\mathrm{OR}=3.416,95 \% \mathrm{CI}=2.139-5.454)$, "often store leftovers in
Table 4 Comparison of food handling behaviors between the case group and the control group

\begin{tabular}{ccccc}
\hline Behavior & \multicolumn{3}{c}{ Group } & \multicolumn{2}{c}{$X^{2}$} & \\
\cline { 2 - 3 } & Case $[n(\%)]$ & Control [n (\%)] & & \\
\cline { 1 - 2 } Often thoroughly heat cooked food purchased from outside before eating \\
no & $117(76.5)$ & $909(70.6)$ & 2.278 & 0.131 \\
yes & $36(23.5)$ & $378(29.4)$ & &
\end{tabular}

Often thoroughly heat milk before drinking

$\begin{array}{lllll}\text { no } & 135(88.2) & 954(74.1) & 14.768 & <0.001 \\ \text { yes } & 18(11.8) & 333(25.9) & & \end{array}$

Often store leftovers in the refrigerator

$\begin{array}{lllll}\text { no } & 63(41.2) & 405(31.5) & 5.875 & 0.015 \\ \text { yes } & 90(58.8) & 882(68.5) & & \end{array}$

Often thoroughly heat leftovers stored in the refrigerator before eating

$\begin{array}{lllll}\text { no } & 95(62.1) & 504(39.2) & 29.597 & <0.001 \\ \text { yes } & 58(37.9) & 783(60.8) & & \end{array}$

Often thoroughly clean raw vegetables or meat purchased from outside

$\begin{array}{lllll}\text { no } & 33(21.6) & 252(19.6) & 0.341 & 0.560 \\ \text { yes } & 120(78.4) & 1035(80.4) & & \end{array}$

Often eat raw seafood

$\begin{array}{lllll}\text { no } & 99(64.7) & 1125(87.4) & 55.298 & <0.001 \\ \text { yes } & 54(35.5) & 162(12.6) & & \end{array}$

Often store raw meat and cooked meat in the same container

$\begin{array}{lllll}\text { no } & 91(59.5) & 1080(83.9) & 53.764<0.001 \\ \text { yes } & 62(40.5) & 207(16.1) & & \end{array}$

Often thoroughly heat green beans prior to eating

$\begin{array}{lllll}\text { no } & 47(30.7) & 202(15.7) & 21.581 & <0.001 \\ \text { yes } & 106(69.3) & 1085(84.3) & & \end{array}$

Often thoroughly boil kitchen utensils to disinfect

$\begin{array}{lllll}\text { no } & 113(73.9) & 926(72.0) & 0.247 & 0.619 \\ \text { yes } & 40(26.1) & 361(28.0) & & \end{array}$

Often buy expired packaged food in supermarkets or shops

$\begin{array}{lllll}\text { no } & 108(70.6) & 945(73.4) & 0.561 & 0.454\end{array}$

yes $\quad$ 45(29.4) 342(26.6)

Often Purchase stale raw vegetables, meat and other ingredients

$\begin{array}{lllll}\text { no } & 105(68.6) & 918(71.3) & 0.485 & 0.486 \\ \text { yes } & 48(31.4) & 369(28.7) & & \end{array}$

Often eat outside the home

\begin{tabular}{lllll} 
no & $123(80.4)$ & $1115(86.6)$ & 4.420 & 0.036 \\
yes & $30(19.6)$ & $172(13.4)$ & & \\
\hline
\end{tabular}

the refrigerator" $(P<0.05, \quad \mathrm{OR}=1.775,95 \% \mathrm{CI}=1.169$ 2.696), "often store raw and cooked meat in the same container" $\quad(P<0.001, \quad$ OR $=4.291, \quad 95 \% \mathrm{CI}=2.722-6.765)$, "often thoroughly cook green beans before eating" $(P<0.001, \mathrm{OR}=2.859,95 \% \mathrm{CI}=1.798-4.545)$, and "often eat raw seafood" $(P<0.001$, OR $=3.250,95 \% \mathrm{CI}=2.136-$ 
Table $\mathbf{5}$ Logistic regression analysis of risk behavior on foodborne acute gastroenteritis

\begin{tabular}{|c|c|c|c|c|c|}
\hline \multirow[t]{2}{*}{ Factors } & \multirow[t]{2}{*}{$\mathrm{B}$} & \multirow[t]{2}{*}{$P$} & \multirow[t]{2}{*}{$\operatorname{Exp}(B)(95 \% C l)$} & \multicolumn{2}{|c|}{ Collinearity Statistics } \\
\hline & & & & Tolerance & VIF \\
\hline Residence & & & & 0.774 & 1.292 \\
\hline urban & Ref. & Ref. & Ref. & & \\
\hline rural & 1.041 & $<0.001$ & $2.832(1.880-4.454)$ & & \\
\hline Gender & & & & 0.847 & 1.181 \\
\hline male & Ref. & Ref. & Ref. & & \\
\hline female & 2.082 & $<0.001$ & $8.019(4.885-13.164)$ & & \\
\hline Often thoroughly heat milk before eating & & & & 0.752 & 1.329 \\
\hline no & 1.54 & $<0.001$ & $4.665(2.526-8.617)$ & & \\
\hline yes & Ref. & Ref. & Ref. & & \\
\hline Often thoroughly heat leftovers stored in the refrigerator & & & & 0.752 & 1.33 \\
\hline no & 1.228 & $<0.001$ & $3.416(2.139-5.454)$ & & \\
\hline yes & Ref. & Ref. & Ref. & & \\
\hline Often store leftovers in the refrigerator & & & & 0.783 & 1.276 \\
\hline no & 0.574 & 0.007 & $1.775(1169-2696)$ & & \\
\hline yes & Ref. & Ref. & Ref. & & \\
\hline Often store raw and cooked meat in the same container & & & & 0.880 & 1.136 \\
\hline no & Ref. & Ref. & Ref. & & \\
\hline yes & 1.456 & $<0.001$ & $4.291(2.722-6.765)$ & & \\
\hline Often thoroughly heat green beans before eating & & & & 0.818 & 1.222 \\
\hline no & 1.05 & $<0.001$ & $2.859(1.798-4.545)$ & & \\
\hline yes & Ref. & Ref. & Ref. & & \\
\hline Often eat raw seafood & & & & 0.964 & 1.101 \\
\hline no & Ref. & Ref. & Ref. & & \\
\hline yes & 1.179 & $<0.001$ & $3.250(2.136-4.946)$ & & \\
\hline Often eat outside the home & & & & 0.909 & 1.101 \\
\hline no & Ref. & Ref. & Ref. & & \\
\hline yes & 0.489 & 0.063 & $1.631(0.973-2.734)$ & & \\
\hline Constant & -7.316 & $<0.001$ & 0.001 & & \\
\hline
\end{tabular}

Ref Reference, VIF Variance Inflation Factor

4.946). There were no obvious collinear issues between independent variables.

\section{Discussion}

Incidence and distribution of foodborne acute gastroenteritis To our knowledge, this is the first survey of foodborne acute gastroenteritis in a community population in Anhui Province, China. The monthly incidence of foodborne acute gastroenteritis recorded in the current study was $10.9 \%$, which was higher than that reported in Italy (8.9\%) [7], France (2.6\%) [4], Japan (3.5\%), Trinidad and Tobago (5.1\%), and British Columbia, Canada (9.2\%). In addition, the monthly incidence of foodborne acute gastroenteritis in the current study was greater than that previously reported in Jiangsu (4.4\%) and Gansu (8.5\%)
[33-37] Provinces, China. Differences in illness prevalence may be related to exposure to risk factors, research design, and/or survey method.

Consistent with previous studies from China, the incidence of foodborne acute gastroenteritis differed in gender, age, education, economic level, and residence. In the current study, the incidence of foodborne acute gastroenteritis in women (15.3\%) was double that of men (7.5\%), subjects aged $\geq 50$ years had the highest incidence of foodborne acute gastroenteritis (23.5\%) and higher education (bachelor's degree or above) was associated with the lowest incidence (6.0\%). The incidence of foodborne acute gastroenteritis was lowest (7.5\%) among respondents with a high income (total annual income greater than 90,000 CNY) and the incidence of 
foodborne acute gastroenteritis in rural residents (13.3\%) was significantly higher than those living in urban areas $(7.6 \%)$.

Meat and meat products, milk and dairy products, aquatic products, eggs and egg products, beans and bean products, and fruits and vegetable were the foods most commonly suspected of causing illness. Meat and meat products were the most commonly suspected foods (58.2\%). The home (40.6\%), street stalls $(24.8 \%)$, and fast food restaurants $(15.2 \%)$ were the most frequently reported locations where suspected foods were consumed. These results indicate that food hygiene inspection and food safety management of street stalls and fast-food restaurants must be increased and that information on proper food handling must be emphasized in the family environment.

\section{Food handling in the family environment}

Thorough heating of food, storing leftovers in the refrigerator, and the disinfection of kitchen utensils are critically important behaviors in the prevention of the growth of microorganisms [38, 39]. However, most people are not educated in the proper handling of food. Inappropriate food handling occurs in food production, food processing, storage, and consumption. In the current study, most respondents reported that they infrequently thoroughly heated milk (75.6\%) and cooked food purchased from outside the home (71.2\%). In addition, as many as $41.6 \%$ of respondents reported storing leftovers in the refrigerator infrequently.

The storage and processing of raw and cooked foods together is often the cause of cross contamination. For example, raw meat and cooked meat are often stored in the same container. In addition, foods containing toxic chemicals such as green beans and seafood are the cause of food poisoning outbreaks in China. The consumption of undercooked or raw foods that contain toxic chemicals, such as green beans and raw seafood, has led to many outbreaks of food poisoning [40, 41]. In the current study, $23.6 \%$ of respondents reported that they often store raw meat and cooked meat in the same container. Most respondents reported that they often thoroughly cook green beans $(82.7 \%)$ and do not usually eat raw seafood $(85.0 \%)$.

These results suggest that inappropriate food handling is prevalent among consumers in the family environment. Previous research has shown that a lack of food safety knowledge is detrimental to the behaviors of food handling [42-44]. These results indicate the importance of increasing education of the typical consumer on proper food handling procedures to produced long-term changes in healthier behaviors.

\section{Food handling behaviors and foodborne acute gastroenteritis}

The present study found differences in food handling behavior between respondents that reported foodborne acute gastroenteritis (case group) and those that did not (control group). The behaviors of infrequently thoroughly heating milk before eating, infrequently storing leftovers in the refrigerator, infrequently thoroughly heating leftovers stored in the refrigerator, often eating raw seafood, often storing raw meat and cooked meat in the same container, and infrequently thoroughly cooking green beans, were $1.2,1.3,1.6,2.8,2.5$, and 2.0 times greater in the case group compared to the control group.

The risk of foodborne acute gastroenteritis was 4.7 times greater in those that responded "no" to "often thoroughly heat milk before eating". Milk that is not thoroughly heated prior to drinking, can increase the risk of foodborne acute gastroenteritis. Drinking cold milk can stimulate the gastrointestinal tract and cause a negative gastrointestinal reaction [45]. In addition, reports of food quality monitoring from several cities indicate that microorganisms such as Staphylococcus aurous have been detected in milk and dairy products sold in stores [46-48]. As such, milk that is not heated prior to drinking may still contain high levels of microorganisms, leading to illness.

Respondents reporting that they do not often store leftovers in the refrigerator or infrequently thoroughly heat leftovers before eating were at a 1.8 and 3.3 times greater risk for foodborne gastroenteritis. Containers used for storage, storage time, and storage temperature are associated with microbial contamination of leftovers. Reusing containers that were used for cooking to store leftovers can cause cross contamination. Rapid bacterial growth occurs in leftovers that are maintained between $4{ }^{\circ} \mathrm{C}\left(40^{\circ} \mathrm{F}\right)$ and $60^{\circ} \mathrm{C}\left(140^{\circ} \mathrm{F}\right)$ [49], and therefore leftovers must be stored in the refrigerator within $2 \mathrm{~h}$. In addition, leftovers should be heated to at least $74^{\circ} \mathrm{C}\left(165^{\circ} \mathrm{F}\right)$ prior to eating in order to reduce the risk of any prior cross contamination and/or inappropriate storage temperature [49].

Infrequently thoroughly cooking green beans before eating was associated with a 2.9 times higher risk of experiencing foodborne acute gastroenteritis in the current study. Green beans can be classified into runner beans (Phaseolus coccineus), yardlong beans (Vigna unguiculata), hyacinth beans (Purple Haricot) and snap beans (P. var. chinensis Hort.). As an important crop worldwide, green beans are low in fat, high in protein, and rich in minerals and multiplex vitamins. However, the consumption of green beans is often the cause of foodborne disease outbreaks in China. Green beans contain two main substances that cause food poisoning: saponin and phytohemagglutinin. Saponin and phytohemagglutinin are relatively resistant to heat and can are only destroyed at temperatures above $100^{\circ} \mathrm{C}\left(212^{\circ} \mathrm{F}\right)$ 
for ten minutes [50]. Short cooking time and low cooking temperatures increase the risk of saponin and phytohemagglutinin poisoning.

Respondents reporting that they often eat raw seafood were 3.3 times more likely to experience foodborne acute gastroenteritis. One possible reason why eating raw seafood increases the risk of foodborne diseases is that seafood has been contaminated by Vibrio parahaemolyticus before consumption. In China, the detection rate of Vibrio parahaemolyticus in seafood is $25-40 \%$ [51]. The bacteria Vibrio parahaemolyticus is a major pathogen in seafood that can cause foodborne diseases outbreaks. For example, of the 2795 foodborne disease outbreaks between 2003 and $2008,14 \%$ were caused by Vibrio parahaemolyticus. Moreover, approximately $28 \%$ of reported outbreaks caused by Vibrio parahaemolyticus were due by aquatic products [52]. Another possible cause that eating raw seafood increases the risk of foodborne diseases is that seafood eaten contains toxins, such as ciguatoxin, histamine, and saxitoxins which can also lead to foodborne diseases [53].

Food handling in the family environment is a complex behavior. Mishandling of food can occur at each step of the food chain process, from purchasing to cleaning, cooking, consuming, and storage. Consumers often do not follow proper food handling practices. Based on our study results, the following food handling behaviors are suggested. First, foods that are not immediately eaten (such as raw seafood, green beans, milk, and leftovers), must be thoroughly heated prior to eating. Second, to reduce cross contamination, containers for cooking food and storing surplus food must be kept separately. Third, leftover food must be stored in the refrigerator in a timely manner.

\section{Limitations}

While the present study provides valuable data on the risk factors associated with foodborne acute gastroenteritis, there are limitation that must be considered. Recall bias may have affected the study results. The data collected relied on respondents accurately relaying past experiences, prior to the start of the study which may result in recall errors. In particular, data on suspected foods and origin of food may be affected. In addition, respiratory diseases can be associated with symptoms similar to those in acute gastroenteritis and therefore, some cases of acute gastroenteritis may have been incorrectly diagnosed. Some respondents that were included in the study therefore, may have had respiratory disease. There was no exclusion criteria for the "control group". And some respondents could not be excluded from the "control group", which may have affected the study results. The "control group" was not paired with the "case group" following some criteria (e.g. gender). The distribution of some variables (e.g. gender) may be disequilibrium between the "case group" and the "control group".

\section{Conclusions}

Inappropriate food handling behaviors in the family environment were associated with foodborne acute gastroenteritis. The behaviors of infrequently thoroughly heating food before eating, infrequently storing leftovers in the refrigerator, and often storing raw meat and cooked meat in the same container are high-risk behaviors associated with foodborne acute gastroenteritis. Further research is needed to explore the most effective methods of resolving inappropriate food handling behaviors in the family environment.

\section{Abbreviations \\ Cl: Confidence intervals; CNY: China Yuan; OR: Odds ratios; VIF: Variance inflation factor}

\section{Acknowledgments}

We wish to thank all the participants for their cooperation in the data collection. The authors thank the staff of the various institutions visited for their contributions.

\section{Funding}

This research was supported by the Key Research Program of Humanities and Social Sciences in Anhui Province Education Department (grant number: SK2015A546), and the Domestic Visiting and Training Project of Outstanding Young Key Teachers in Universities in Anhui Province (grant number: gxfx2017069). The funders had no role in study design, data collection, analysis and interpretation and writing the manuscript.

\section{Availability of data and materials}

Due to privacy regulations, it is not possible to deposit data to a public repository. Interested researchers are kindly asked to directly address Ms. Yujuan Chen with appropriate requests for data. The authors confirm that any interested reader who contacts Ms. Yujuan Chen will be provided with an identified dataset (School of Public Health, Wannan Medical College, Wuhu 241,002, China. Email: 57903241@qq.com).

\section{Authors' contributions}

YJC conceived of the study. YJC and YFW participated in the design of questionnaire. YJC, JGS, BFC, SSD, JJD and LD performed acquisition and input of data. BFC and SSD performed analysis and interpretation of data. YJC drafted the first and subsequent version of the manuscript. YFW and JGS contributed to drafting subsequent versions of the manuscript. LD was involved in the critical revision of the manuscript for intellectual content and given final approval of the version to be published. All authors are responsible for appropriate portions of the content. All authors agreed to be accountable for all aspects of the content in ensuring that questions related to the accuracy or integrity of any part of the content are appropriately investigated and resolved. All authors read and approved the final manuscript.

\section{Ethics approval and consent to participate}

The current study has received approval from the medical ethics committee of Wannan Medical College, Anhui Province, China. Signed informed consent was obtained from all participants or their legal representative. For those participants under the age of 16 , consent to participate was obtained from their parents or legal guardians, and the informed consent was provided by their parents or legal guardians on their behalf.

\section{Consent for publication}

Not applicable.

\section{Competing interests}

The authors declare that they have no competing interests.

\section{Publisher's Note}

Springer Nature remains neutral with regard to jurisdictional claims in published maps and institutional affiliations. 


\section{Received: 14 March 2018 Accepted: 15 November 2018} Published online: 26 November 2018

\section{References}

1. McLinden T, Sargeant JM, Thomas MK, et al. Component costs of foodborne illness: a scoping review. BMC Public Health. 2014;14:509.

2. Estimates of the global burden of foodborne diseases [Internet]. Geneva: World Health Organization. http://www.who.int/en/news-room/detail/03-122015-who-s-first-ever-global-estimates-of-foodborne-diseases-find-childrenunder-5-account-for-almost-one-third-of-deaths.

3. Gould LH, Walsh KA, Vieira AR, et al. Surveillance for foodborne-disease outbreaks-United States, 1998-2008. Morb Mortal Wkly Rep. 2013;62:1-34.

4. OzFoodNet Working Group. Foodborne disease investigation across Australia: annual report of the OzFoodNet network, 2003. Commun Dis Intell. 2004;28(3):359-89.

5. Masoumi Asl H, Gouya MM, Soltan-dallal MM, et al. Surveillance for foodborne disease outbreaks in Iran, 2006-2011. Med J Islam Repub Iran. 2015;29(3):285

6. Van Cauteren D, De Valk H, Vaux S, et al. Burden of acute gastroenteritis and healthcare-seeking behavior in France: a population-based study. Epidemiol Infect. 2011;140(4):697-705

7. Baumann-Popczyk A, Sadkowska-Todys M, Rogalska J, et al. Incidence of self-reported acute gastrointestinal infections in the community in Poland: a population-based study. Epidemiol Infect. 2012;140(7):1173-84.

8. Scavia G, Baldinelli F, Busani $L$, et al. The burden of self-reported acute gastrointestinal illness in Italy: a retrospective survey, 2008-2009. Epidemiol Infect. 2012;140(7):1193-206.

9. Ingram M, John J, Applewhaite T, et al. Population-based estimates of acute gastrointestinal and foodborne illness in Barbados: a retrospective crosssectional study. J Health Popul Nutr. 2013;31(4):81-97.

10. Chen Y, Yan W-X, Zhou Y-J, et al. Burden of self-reported acute gastrointestinal illness in China: a population-based survey. BMC Public Health. 2013;13(1):456.

11. Mohammed FA. The incidence of enterobacteriaceae causing food poisoning in some meat products. Adv J Food Sci Technol. 2011;3(2):116-21.

12. Redmond EC, Griffith CJ. The importance of hygiene in the domestic kitchen: implications for preparation and storage of food and infant formula. Perspect Public Health. 2009;129(2):69-76.

13. European Food Safety Authority (EFSA). The European Union summary report on trends and sources of zoonoses, zoonotic agents and food-borne outbreaks in 2009. Sci Rep EFSA ECDC Eur Food Saf Authority J. 2011;9(3):287.

14. National Health and Family Planning Commission of the People's Republic of China. Notification of national food poisoning incidents in 2015. Available online: Http://www.nhfpc.gov.cn/yjb/s7859/201604/ 8d34e4c442c54d33909319954c43311c.shtml.

15. Ding X-I. Analysis of characteristics of national food poisoning events from 2002-2012 and discussion on precautionary measure. Jiangsu J Prev Med. 2013;24(4):14-5.

16. Wang M-Q, Liu X-M, Wang Z-T. Studies on National Surveillance System for food contaminations and foodborne diseases in China. Chin J Food Hyg. 2006;18(6):491-6.

17. Sheng H-P. Status of foodborne disease surveillance in China. China Food Saf Mag. 2015;13:46-8.

18. Zhou W-M. Survey of food poisoning caused by pesticide residues in vegetables. Jiangsu J Prev Med. 2007;18(4):39-40.

19. Zhang $Y$. Investigation of two food poisoning incidents caused by green beans. Shanghai J Prev Med. 2011;23(7):349.

20. Lin S-Z, Pang G-Q, Lu Y-L, et al. Investigation report of one migrant workers food poisoning caused by green bean. J Med Pest Control. 2013;29(6):685-6.

21. Liu $Y-X$, Wang $H-W$. Investigation report of one food poisoning caused by seafood. J Pub Health Prev Med. 2013;24(1):109-10.

22. Tang Y-J. A survey of food poisoning caused by contaminated leftovers of Bacillus cereus. Pract Prev Med. 2009;16(3):777-8.

23. Wang B, Zhang X-M, Gao J-Z, et al. Investigation of a case of food poisoning induced by Staphylococcus aureus. Occup Health. 2008;24(6):544-5.

24. Chen F-Y, Li S-X, Liu S-J. Investigation of one food poisoning caused by Bacillus cereus. Jiangxi Med J. 2010;45(9):934-5.

25. Shi L-Y. A food poisoning caused by bagged milk. Chin J School Health. 2003;24(2):150.

26. Yang H-X, Ma C-L, Guo W-Z. Student food poisoning caused by drinking bagged milk. Chin J School Health. 2003;24(1):56.
27. Yuan B-J, Dai J-H. Investigation report on food poisoning caused by bagged milk in children. Jiangsu Health Care. 2001;3(4):32.

28. National Health and Family Planning Commission of the People's Republic of China. Notification of national food poisoning incidents in 2014. Available online: Http://www.nhfpc.gov.cn/yjb/s3585/201502/ 91fa4b047e984d3a89c16194722ee9f2.shtml.

29. National Health and Family Planning Commission of the People's Republic of China. Notification of national food poisoning incidents in 2013. Available online: Http://www.nhfpc.gov.cn/yjb/s3585/201402/ f54f16a4156a460790caa3e991c0abd5.shtml.

30. Adikari AMNT, Fathima Rizana MS, Priyanwada Amarasekara T. Food safety practices in a teaching hospital in Sri Lanka. Procedia Food Sci. 2016;6:65-7.

31. Nesbitt A, Majowics S, Finley R, et al. High-risk food consumption and food safety practices in a Canadian community. J Food Prot. 2009;72:2575-86.

32. Smigic N, Djekic I, Martins ML, et al. The level of food safety knowledge in food establishments in three European countries. Food Control. 2016;63:187-94.

33. Kubota K, Kasuga K, Iwasaki E, et al. Estimating the burden of acute gastroenteritis and foodborne illness caused by campylobacter, Salmonella, and Vibrio parahaemolyticus by using population-based telephone survey data, Miyagi prefecture, Japan, 2005 to 2006. J Food Prot. 2011;74(10):1592-8.

34. Lakhan C, Badrie N, Ramsubhag A, et al. Burden and impact of acute gastroenteritis and foodborne pathogens in Trinidad and Tobago. J Health Popul Nutr. 2013;31(4):530-42.

35. Thomas MK, Majowicz SE, MacDougall L, et al. Population distribution and burden of acute gastrointestinal illness in British Columbia, Canada. BMC Public Health. 2006;6:307.

36. Dai Y, Yuan B-J, Luo Y-Z, et al. Study on the burden of food-borne gastrointestinal diseases in 2009, Jiangsu province. Jiangsu J Prev Med. 2010;21(4):4-6.

37. Sang $X-L$, Liang $X-C$, Chen $Y$, et al. Estimating the burden of acute gastrointestinal illness in the community in Gansu Province, northwest China, 2012-2013. BMC Public Health. 2014;14:787.

38. Farahat MF, El-Shafie MM, Waly MI. Food safety knowledge and practices among Saudi women. Food Control. 2015;47:427-35.

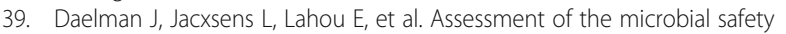
and quality of cooked chilled foods and their production process. Int J Food Microbiol. 2013;160(3):193-200.

40. Liao Y, Li Y, Wu S, et al. Risk factors for Vibrio parahaemolyticus infection in a southern coastal region of China. Foodborne Pathog Dis. 2015;12(11):881-6.

41. Nesbitt A, Thomas MK, Marshall B, et al. Baseline for consumer food safety knowledge and behavior in Canada. Food Control. 2014;38:157-73.

42. Jevsnik M, Hlebec V, Raspor P. Food safety knowledge and practices among food handlers in Slovenia. Food Control. 2008;19:1107-18.

43. Mullan BA, Wong C, Kothe EJ. Predicting adolescents' safe food handling using an extended theory of planned behavior. Food Control. 2013;31:454-60.

44. Jianu C, Chis A. Study on the hygiene knowledge of food handlers working in small and medium-sized companies in western Romania. Food Control. 2012;26:151-6.

45. Gu J. Drinking milk - "Five unsuitable". New Countryside. 2003;2:27.

46. Pan F, Han L, Zhao H-L. Contamination status of foodborne pathogen in commercial foods in Daxing District of Beijing City from 2010-2014. Occup Health. 2017;33(10):1335-8.

47. Yan $X-Y$, Zhang $C-Y$, Huang $S-H$, et al. Analysis of contamination status of Salmonella and Staphylococcus aureus in some commercial food products in Kaifeng City of Henan Province from 2011 to 2015. J Med Pest Control. 2017;33(4):393-5.

48. Li X-C, Ma L-K, Yang C, et al. Monitoring and analysis of microbial contamination of food in Nanjing, 2010-2015. Modern Prev Med. 2017;44(6): 1007 1010, 1027.

49. United States Department of Agriculture. Food Safety Education. Available online: https: // www.fsis.usda.gov/wps/portal/fsis/topics/food-safetyeducation/get-answers/food-safety-fact-sheets/safe-food-handling/leftoversand-food-safety.

50. Phaseolus vulgaris. Wikipedia. https://en.wikipedia.org/wiki/Phaseolus_vulgaris

51. Han X-L, Zhang H-Y, Cao M-X, et al. Analysis on current pollution of Vibrio parahemolyticus in seafood in China and its controlling strategy. Food Ferment Ind. 2015;41(7):263-7.

52. Wu Y-N, Wen J, Ma Y, et al. Epidemiology of foodborne disease outbreaks caused by Vibrio parahaemolyticus, China, 2003-2008. Food Control. 2014;46:197-202.

53. Wang $X-Z$, Cheng $Y$, Li N, et al. Occurrence and Seasonal Variations of Lipophilic Marine Toxins in Commercial Clam Species along the Coast of Jiangsu, China. Toxins. 2016;8:8. https://doi.org/10.3390/toxins8010008. 